\author{
Henryk Zawadzki \\ Katedra Matematyki \\ Uniwersytet Ekonomiczny w Katowicach
}

\title{
Analiza dynamiki modeli wzrostu gospodarczego za pomocą środowiska obliczeniowego Mathematica
}

\section{Streszczenie}

Podstawowy aparat matematyczny teorii wzrostu gospodarczego (w przypadku modeli z czasem ciągłym) stanowią równania różniczkowe oraz sterowanie optymalne, czyli wyznaczanie rozwiązań równań różniczkowych spełniających określone warunki i optymalizujących pewien funkcjonał całkowy. W artykule przedstawiono (na przykładzie modeli wzrostu Mankiwa-Romera-Weila oraz Lucasa-Uzawy) wybrane możliwości programu Mathematica w zakresie: numerycznego rozwiązywania równań różniczkowych (równań ruchu) i wyznaczania optymalnych wartości funkcjonałów (całkowitej zdyskontowanej użyteczności) w przypadku, gdy rozwiązania optymalne wyznaczone są jedynie w sposób numeryczny, symbolicznego różniczkowania rozwiązań równań różniczkowych, wyrażonych za pomocą pewnej klasy funkcji specjalnych - funkcji hipergeometrycznych Gaussa oraz graficznej prezentacji rozwiązań równań różniczkowych.

Słowa kluczowe: Mathematica, równania różniczkowe, modele wzrostu gospodarczego, sterowanie optymalne.

\section{Wprowadzenie}

Teoria wzrostu gospodarczego jest niewątpliwie jednym z najbardziej sformalizowanych działów ekonomii. Stosowany w niej aparat matematyczny obejmuje 
m.in. teorię równań różniczkowych i różnicowych, teorię sterowania optymalnego (lub ogólniej - optymalizację dynamiczną) oraz jakościową teorię układów dynamicznych. Wyznaczanie ścieżek wzrostu (optymalnych ścieżek wzrostu) modelowanych gospodarek sprowadza się do rozwiązywania równań różniczkowych lub przynajmniej jakościowej analizy dynamiki układów generowanych przez te równania. Niezwykle pomocnymi, a czasami niezastąpionymi narzędziami wspomagającymi analizę matematycznych modeli wzrostu są programy komputerowe zwane systemami algebry komputerowej (computer algebra systems, CAS). Jednym z głównych programów tego typu, a właściwie środowiskiem służącym do naukowych obliczeń numerycznych i symbolicznych, sporządzania dwuwymiarowej i trójwymiarowej grafiki oraz interaktywnych dokumentów jest Mathematica, której producentem jest Wolfram Research Inc. z siedzibą w Champaign IL, USA. W artykule przedstawiono (na przykładzie modeli wzrostu Mankiwa-Romera-Weila oraz Lucasa-Uzawy) wybrane możliwości programu Mathematica w zakresie:

- numerycznego rozwiązywania równań różniczkowych (równań ruchu) oraz wyznaczania optymalnych wartości funkcjonałów (całkowitej zdyskontowanej użyteczności - lifetime utility) w przypadku, gdy rozwiązania optymalne wyznaczone są jedynie w sposób przybliżony (numeryczny),

- symbolicznego różniczkowania rozwiązań równań różniczkowych, wyrażonych za pomocą pewnej klasy funkcji specjalnych - funkcji hipergeometrycznych Gaussa,

- graficznej prezentacji rozwiązań równań różniczkowych.

\section{Model Mankiwa-Romera-Weila ze sterowaniem}

T. Tokarski [2011] przedstawia pewien problem sterowania optymalnego w neoklasycznym modelu wzrostu Mankiwa-Romera-Weila ([Mankiw, Romer i Weil 1992]. Problem polega na wyznaczeniu ścieżek czasowych stóp inwestycji $s_{K}(t)$ oraz $s_{H}(t)$ odpowiednio w kapitał rzeczowy i ludzki, które maksymalizują całkę preferencji (łączną zdyskontowaną użyteczność) typowego konsumenta daną wzorem:

$$
U=\int_{0}^{+\infty} \frac{\left\{\left[1-s_{K}(t)-s_{H}(t)\right] y(t)\right\}^{1-\sigma}-1}{1-\sigma} e^{-\rho t} d t .
$$

W powyższej całce $y(t)=Y(t) / L(t)$ jest wielkością produkcji $Y(t)$ przypadającej na pracującego, przy czym liczba pracujących $L(t)$ rośnie wykładniczo, zgodnie ze wzorem $L(t)=L_{0} e^{n t}$, w którym $L_{0}>0$ jest zasobem pracy w chwili początkowej $t=0$, a $n>0$ stopą wzrostu zasobu liczby pracujących. Wielkości $\rho>0$ oraz 
$\sigma \in(0,1) \cup(1,+\infty)$ są parametrami oznaczającymi odpowiednio stopę dyskontową oraz współczynnik względnej niechęci konsumenta do ryzyka.

W rozważanym modelu funkcja produkcji jest funkcją Cobba-Douglasa

$$
Y(t)=[K(t)]^{\alpha}[H(t)]^{\beta}[A(t) L(t)]^{1-\alpha-\beta},
$$

w której $K(t), H(t)$ i $A(t)$ oznaczają kolejno: zasoby kapitału rzeczowego, kapitału ludzkiego oraz zasoby wiedzy. Te ostatnie określone są wzorem $A(t)=A_{0} e^{g t}$, w którym $A_{0}>0$ oznacza zasoby wiedzy w chwili $t=0$, a $g>0$ stopę wzrostu postępu technicznego. Dodatnie parametry $\alpha$ i $\beta$ spełniające warunek $\alpha+\beta<1$, oznaczają elastyczność produkcji $Y$ względem kapitału rzeczowego $K$ i kapitału ludzkiego $H$. Zakładając, że dynamika kapitału $K$ i kapitału $H$ opisana jest równaniami różniczkowymi:

$$
\begin{aligned}
& K^{\prime}(t)=s_{K}(t) Y(t)-\delta_{K} K(t), \\
& H^{\prime}(t)=s_{H}(t) Y(t)-\delta_{H} H(t),
\end{aligned}
$$

gdzie: $\delta_{K}, \delta_{H} \in(0,1)$ są stopami deprecjacji kapitałów, wspomniany problem sterowania optymalnego można sformułować następująco: znaleźć ścieżki czasowe stóp inwestycji $s_{K}(t)$ oraz $s_{H}(t)$, które maksymalizują łączną zdyskontowaną użyteczność (1), gdy zmienne stanu $k(t)=\frac{K(t)}{L(t)}, h(t)=\frac{K(t)}{L(t)}$ oraz $y(t)$ spełniają
równania ruchu

$$
\begin{gathered}
k^{\prime}(t)=s_{K}(t) y(t)-\left(\delta_{K}+n\right) k(t), \\
h^{\prime}(t)=s_{H}(t) y(t)-\left(\delta_{H}+n\right) h(t), \\
y(t)=A_{0}^{1-\alpha-\beta} e^{(1-\alpha-\beta) g t}[k(t)]^{\alpha}[h(t)]^{\beta},
\end{gathered}
$$

zmienne sterujące $s_{K}(t)$ i $s_{H}(t)$ spełniają w każdym momencie $t \in[0,+\infty)$ warunki $s_{K}(t), s_{H}(t) \in(0,1)$ oraz $s_{K}(t)+s_{H}(t) \in(0,1)$, a warunki początkowe mają postać

$$
k(0)=k_{0}, h(0)=h_{0},
$$

gdzie $k_{0}, h_{0}>0$ oznaczają początkowe zasoby kapitału rzeczowego i ludzkiego.

T. Tokarski [2011] dowiódł, że przy dodatkowym założeniu, iż stopy inwestycji $s_{K}(t)$ i $s_{H}(t)$ są stałe w czasie, optymalnymi ścieżkami czasowymi, czyli ścieżkami maksymalizującymi funkcjonał $U$, są:

$$
s_{K}(t) \equiv \frac{\alpha\left(g+\delta_{K}+n\right)}{\rho+\delta_{K}+n+\sigma g},
$$




$$
s_{H}(t) \equiv \frac{\beta\left(g+\delta_{H}+n\right)}{\rho+\delta_{H}+n+\sigma g} .
$$

Chcąc obliczyć maksymalną wartość funkcjonału $U$, należałoby podstawić do układu równań (5), (6) produkcję per capita y(t) określoną wzorem (7) oraz przedstawione wzorami (9) i (10) optymalne sterowania. Po rozwiązaniu tego układu (dla zadanych warunków początkowych (8)) należałoby podstawić jego rozwiązania i do wzoru (7), a otrzymaną w ten sposób funkcję $y(t)$ - do funkcji podcałkowej funkcjonału (1). Ponieważ jednak otrzymanie dokładnych rozwiązań wspomnianego wyżej, nieliniowego układu nie jest możliwe, pozostaje jedynie wyznaczyć jego rozwiązanie przybliżone (numeryczne), które pozwala na oszacowanie maksymalnej wartości $U$, czyli łącznej, zdyskontowanej użyteczności konsumenta. Dla ustalonej wartości parametrów za pomocą Mathematica można oszacować maksymalną wartość funkcjonału $U$ dla sterowań optymalnych (9), (10), mimo że nie jest znana postać analityczna optymalnych ścieżek czasowych zmiennych stanu $k$ oraz $h$.

Ustalmy wartości parametrów modelu oraz warunki początkowe:

$$
\begin{aligned}
\ln [1]:=\mathrm{A} 0=1 ; \delta \mathrm{K}=0.03 ; \delta \mathrm{H}=0.02 ; \alpha=0.35 ; \beta=0.4 ; \\
\quad \mathrm{n}=0.02 ; \mathrm{g}=0.01 ; \mathrm{k} 0=1 ; \mathrm{h} 0=1 ; \sigma=0.5 ; \rho=0.01 ;
\end{aligned}
$$

Dla powyższych wartości parametrów obliczmy optymalne wartości zmiennych sterujących (wzory (9) i (10)):

$$
\begin{aligned}
& \ln [3]=\left\{\mathrm{sK}=\frac{\alpha(\mathrm{g}+\delta \mathrm{K}+\mathrm{n})}{\rho+\delta \mathrm{K}+\mathrm{n}+\sigma \mathrm{g}}, \mathrm{sH}=\frac{\beta(\mathrm{g}+\delta \mathrm{H}+\mathrm{n})}{\rho+\delta \mathrm{H}+\mathrm{n}+\rho \mathrm{g}}\right\} \\
& \text { Out[i] }=\{0.323077,0.399202\}
\end{aligned}
$$

Następnie za pomocą instrukcji NDSolve wyznaczmy w sposób numeryczny rozwiązanie ,sol” układu (5), (6) i narysujmy wykresy tworzących to rozwiązanie funkcji $k(t)$ i $h(t)$ w przedziale $[0,100]$ (rys. 1).

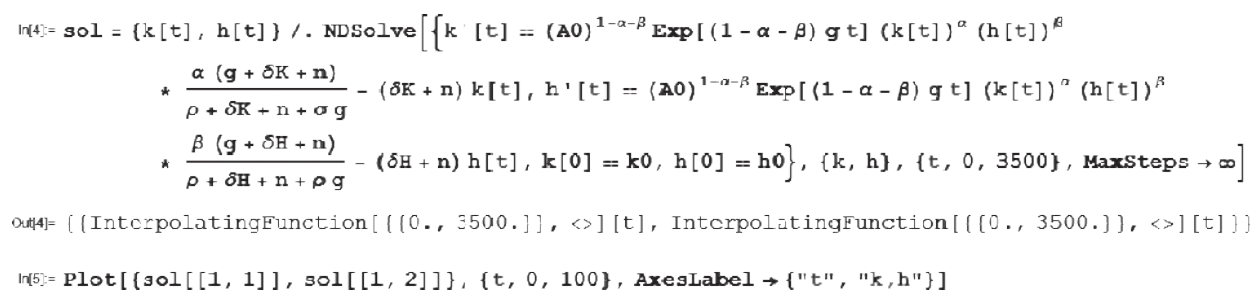




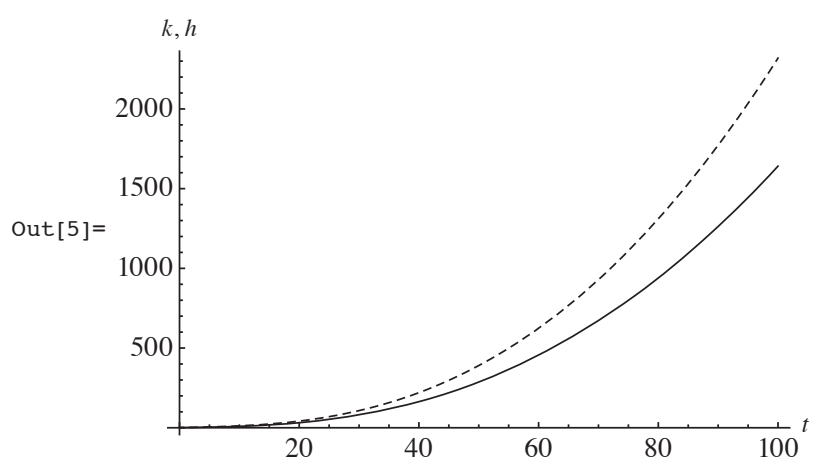

Rys. 1. Ścieżki czasowe kapitału rzeczowego $k$ (krzywa położona niżej) i kapitału ludzkiego $h$ w przedziale [0, 100]

Źródło: opracowanie własne.

Obliczmy teraz wartości funkcjonału $U$, całkując w przedziale $[0, T]$, dla kilku dużych wartości czasu $T$, na przykład $T=1000,1500,2000,2500,3000$ oraz 3500.

$$
\begin{aligned}
\ln \left[(6)=\operatorname{Table}\left[\int _ { 0 } ^ { T } \frac { 1 } { 1 - \sigma } \left(\left((1-s K-s H) *(\mathbf{A} 0)^{1 \alpha \beta} \operatorname{Exp}[(1-\alpha-\beta) g t]\right.\right.\right.\right. \\
\left.\left.\left.\quad *(\operatorname{sol}[[1,1]])^{\alpha}(\operatorname{sol}[[1,2]])^{\beta}\right)^{1-\sigma}-1\right) \operatorname{Exp}[-\rho t] d t / / \mathbf{N}_{*}(T, 1000,3500,500\}\right]
\end{aligned}
$$

Outbl= $\{2320.11,2342.42,2344.26,2344.41,2344.42,2344.42\}$

Jak można zauważyć, w miarę wzrostu $T$ wartości funkcjonału stabilizują się i można przyjąć, że maksymalna wartość łącznej zdyskontowanej użyteczności konsumenta wynosi $U_{\max } \approx 2344.42$.

\section{Model Lucas-Uzawy i funkcja hipergeometryczna Gaussa}

R. Boucekkine i J.R. Ruiz-Tamarit [2008] rozważyli dwusektorowy, endogeniczny model wzrostu Lucasa-Uzawy i związany z nim problem optymalizacji dynamicznej

$$
U=\int_{0}^{\infty} \frac{c(t)^{1-\sigma}-1}{1-\sigma} N(t) e^{-\rho t} d t \rightarrow \max
$$

$\mathrm{z}$ równaniami ruchu

$$
\begin{gathered}
K^{\prime}(t)=A K(t)^{\beta}(u(t) N(t) h(t))^{1-\beta}-p K(t)-N(t) c(t), \\
h^{\prime}(t)=\delta(1-u(t)) h(t)-\theta h(t),
\end{gathered}
$$


warunkami

$$
\begin{gathered}
K(0)=K_{0}, \quad h(0)=h_{0}, \quad N(0)=N_{0}, \quad K(t) \geq 0, \quad h(t) \geq 0 \\
c(t) \geq 0, \quad u(t) \in[0,]]
\end{gathered}
$$

oraz warunkami transwersalności

$$
\lim _{t \rightarrow \infty} \lambda_{1}(t) K(t) \exp (-\rho t)=0, \quad \lim _{t \rightarrow \infty} \lambda_{2}(t) h(t) \exp (-\rho t)=0 .
$$

W modelu tym zmiennymi są: zasoby kapitału fizycznego $K$ i kapitału ludzkiego $h$, wielkość populacji $N$ (której egzogeniczna, stała w czasie stopa wzrostu jest równa $n$ ), strumień konsumpcji per capita $c$ oraz frakcja czasu poświęconego na produkcję dóbr konsumpcyjnych $u$. Dwie ostatnie zmienne, czyli $c$ i $u$ są zmiennymi sterującymi modelu. Parametrami (oprócz stopy wzrostu populacji $n$ ) są: współczynnik względnej awersji do ryzyka $\sigma$, stopa dyskontowa $\rho$, współczynniki postępu technologiczno-organizacyjnego w sektorze produkcyjnym i edukacyjnym $A$ i $\delta$, elastyczność produkcji względem kapitału fizycznego $\beta$ oraz stopy deprecjacji kapitału fizycznego i ludzkiego $p$ i $\theta$. Parametry spełniają warunki: $\delta, \rho$, $\sigma>0, n, p, \theta \geq 0, \beta \in(0,1), \rho>n$, oraz $\delta+n>\theta+\rho$.

Autorom udało się wyznaczyć w sposób analityczny optymalne ścieżki czasowe zasobów kapitału fizycznego $K$, kapitału ludzkiego $h$ oraz zmiennych sterujących $c$ i $u$ w zamkniętej formie za pomocą funkcji hipergeometrycznej Gaussa ${ }_{2} F_{1}(\alpha, \beta, \gamma ; x)$. Funkcję tę, określoną dla $\gamma \neq 0,-1,-2, \ldots$ można przedstawić $\mathrm{w}$ postaci szeregu:

$$
{ }_{2} F_{1}(\alpha, \beta, \gamma ; x)=\sum_{n=0}^{\infty} \frac{(\alpha)_{n}(\beta)_{n}}{(\gamma)_{n}} \frac{x^{n}}{n !},
$$

gdzie: $(\delta) n=\delta(\delta+1) \ldots(\delta+n-1)$ jest symbolem Pochhammera. Szereg (12), zwany szeregiem hipergeometrycznym, jest dla $|x|<1$ zbieżny jednostajnie i bezwzględnie. Dla $\gamma>\beta>0$ funkcję ${ }_{2} F_{1}$ można także przedstawić jako całkę

$$
{ }_{2} F_{1}(\alpha, \beta, \gamma ; x)=\frac{\Gamma(\gamma)}{\Gamma(\beta) \Gamma(\gamma-\beta)} \int_{0}^{1} t^{\beta-1}(1-t)^{\gamma-\beta-1}(1-t x)^{-\alpha} d t .
$$

Wzór powyższy znany jest jako reprezentacja całkowa Eulera funkcji hipergeometrycznej Gaussa. Wzory, które umożliwiają przedłużenie analityczne funkcji ${ }_{2} F_{1}$ poza przedział $|x|<1$, podaje m.in. [Korn i Korn 1983, cz. 1, s. 270].

Przykładowo ścieżka kapitału $K$ ma postać:

$$
\begin{aligned}
& K(t)=K_{0}\left(\frac{\lambda_{1}(0)}{\lambda_{2}(0)}\right)^{1 / \beta}\left(\frac{\varepsilon}{\delta+n+p-\theta}\right)^{1 /(1-\beta)} \frac{{ }_{2} F_{1}(t)}{{ }_{2} F_{1}(0)} \times \\
& \times \exp \left\{\frac{(\delta+n+p-\theta)(\beta-\sigma)-\beta(\rho+p-n \sigma)}{\beta \sigma} t\right\} \times \\
& \times\left[-1+\exp \left\{\frac{(1-\beta)(\delta+n+p-\theta)}{\beta}\right\} t+\frac{\delta+n+p-\theta}{\varepsilon}\left(\frac{\lambda_{1}(0)}{\lambda_{2}(0)}\right)^{(\beta-1) / \beta}\right]^{1 /(1-\beta)}
\end{aligned}
$$


We wzorze (14)

$$
{ }_{2} F_{1}(t)={ }_{2} F_{1}\left(a, b, \gamma ;\left(1-\frac{\delta+n+p-\theta}{\varepsilon}\left[\frac{\lambda_{1}(0)}{\lambda_{2}(0)}\right]^{\frac{\beta-1}{\beta}}\right) \times \exp \left[-\frac{(1-\beta)(\delta+n+p-\theta)}{\beta} t\right]\right),
$$

gdzie

$$
\begin{gathered}
a=-\frac{(\delta+n+p-\theta)(\beta-\sigma)-\beta(\rho+p-n \sigma-p \sigma)}{\sigma(\delta+n+p-\theta)(1-\beta)}, \\
b=-\frac{\beta-\sigma}{\sigma(1-\beta)}, \\
\gamma=1+a, \\
\varepsilon=A \beta\left[(1-\beta) A N_{0} / \delta\right]^{(1-\beta) / \beta},
\end{gathered}
$$

natomiast $\lambda_{1}=\lambda_{1}(t)$ oraz $\lambda_{2}=\lambda_{2}(t)$ są mnożnikami Lagrange'a występującymi w hamiltonianie wartości bieżącej:

$$
H^{c}=\frac{c^{1-\sigma}-1}{1-\sigma} N+\lambda_{1}\left[A K^{\beta}(u N h)^{1-\beta}-p K-N c\right]+\lambda_{2}[\delta(1-u) h-\theta h] .
$$

Wartości $\lambda_{1}(0)$ i $\lambda_{1}(0)$ mnożników Lagrange'a w chwili początkowej $t=0$ wyznaczane są z układu równań:

$$
\begin{gathered}
\frac{{ }_{2} F_{1}(0)}{{ }_{2} \tilde{F}_{1}(0)}=-\frac{(1-\beta) \varepsilon \sigma}{[(\delta-\theta)(1-\sigma)+n-\rho] \beta} \frac{K_{0}}{h_{0}}\left(\frac{\lambda_{1}(0)}{\lambda_{2}(0)}\right)^{1 / \beta}, \\
\frac{K_{0}}{{ }_{2} F_{1}(0)}\left(\frac{\lambda_{1}(0)}{\lambda_{2}(0)}\right)^{\frac{1}{\beta}}=-\frac{\sigma \beta N_{0}\left[\lambda_{2}(0)\right]^{-1 / \sigma}[(\delta+n+p-\theta) / \varepsilon]^{(\sigma-\beta) /[\sigma(1-\beta)]}}{(\delta+n+p-\theta)(\beta-\sigma)-\beta(\rho+p-n \sigma-p \sigma)},
\end{gathered}
$$

w którym

$$
{ }_{2} \tilde{F}_{1}(t)={ }_{2} F_{1}\left(a-1, b, \gamma ;\left(1-\frac{\delta+n+p-\theta}{\varepsilon}\left[\frac{\lambda_{1}(0)}{\lambda_{2}(0)}\right]^{\frac{\beta-1}{\beta}}\right) \times \exp \left[-\frac{(1-\beta)(\delta+n+p-\theta)}{\beta} t\right]\right) .
$$

Wzór (14) zachodzi, gdy parametry modelu spełniają warunki:

$$
\begin{gathered}
(\delta+n+p-\theta)(\beta-\sigma)-\beta(\rho+p-n \sigma-p \sigma)<-\sigma(1-\beta)(\delta+n+p-\theta)<0, \\
(\delta-\theta)(1-\sigma)+n-\rho<0
\end{gathered}
$$

oraz układ równań (16), (17) ma dokładnie jedno dodatnie rozwiązanie.

Korzyści wynikające z wyprowadzonych w [Boucekkinei Ruiz-Tamarit 2008] wzorów określających ścieżki czasowe zmiennych $K, h, u$ i $c$ stają się widoczne dopiero wtedy, gdy mamy do dyspozycji odpowiednie oprogramowanie. Mathematica pozwala nie tylko na obliczanie wartości liczbowych wspomnianych wyżej zmiennych w dowolnej chwili $t \geq 0$, lecz także na ich różniczkowanie i rysowanie ścieżek czasowych. 
Za pomocą programu Mathematica można (dla ustalonych wartości parametrów i zadanych warunków początkowych) z dużą dokładnością wyznaczyć przybliżone, dodatnie rozwiązania $\lambda_{1}(0)$ i $\lambda_{2}(0)$ złożonego, nieliniowego układu równań (16), (17). Wystarczy w tym celu wykorzystać funkcję Hypergeometric2F1 $[a, b, c, z]$ oraz instrukcje ContourPlot i FindRoot tego programu. Wspomniana funkcja oblicza dla rzeczywistych lub zespolonych wartości parametrów $a, b, c$ oraz argumentu $z$, wartości hipergeometrycznej funkcji Gaussa ${ }_{2} F_{1}(a, b, c ; z)$. Instrukcja ContourPlot umożliwia przybliżoną, wizualną lokalizację rozwiązań wspomnianego układu, będących punktami przecięcia krzywych wyznaczonych przez równania tego układu. Wstępna lokalizacja rozwiązania pozwala z kolei na wyznaczenie za pomocą instrukcji FindRoot dokładnych wartości pierwiastków $\lambda 1(0)$ i $\lambda 2(0)$.

Ustalmy wartości parametrów i wartości początkowe modelu Lucasa-Uzawy oraz obliczmy występujące we wzorach (15) wielkości a, b, $\gamma$ i $\varepsilon$.

$$
\begin{aligned}
\operatorname{In}[1]= & \operatorname{Clear}[\mathrm{N} 0, \mathrm{n}, \mathrm{A}, \delta, \mathrm{p}, \theta, \rho, \beta, \sigma, \mathrm{K} 0, \mathrm{~h} 0] \\
\operatorname{In}[2]= & \mathrm{N} 0=1 ; \mathrm{n}=0.01 ; \mathrm{A}=1 ; \delta=0.06 ; \mathrm{p}=0.05 ; \theta=0.01 ; \\
& \rho=0.04 ; \beta=0.45 ; \sigma=1.2 ; \mathrm{K} 0=1 ; \mathrm{h} 0=0.25 ; \\
\operatorname{In}[4]=\boldsymbol{\epsilon} & =\beta * \mathrm{~A} *((1-\beta) * \mathrm{~A} * \mathrm{~N} 0 / \delta) \wedge((1-\beta) / \beta) ; \\
\mathrm{a} & =-\frac{(\delta+\mathrm{n}+\mathrm{p}-\theta)(\beta-\sigma)-\beta(\rho+\mathrm{p}-\mathrm{n} \sigma-\mathrm{p} \sigma)}{\sigma(\delta+\mathrm{n}+\mathrm{p}-\theta)(1-\beta)} ; \\
& \mathrm{b}=-\frac{\beta-\sigma}{\sigma(1-\beta)} ; \\
& \gamma=1+\mathrm{a} ;
\end{aligned}
$$

Zdefiniujmy lewe i prawe strony układu równań (16), (17) oraz narysujmy krzywe wyznaczone przez równania tego układu (rys. 2).

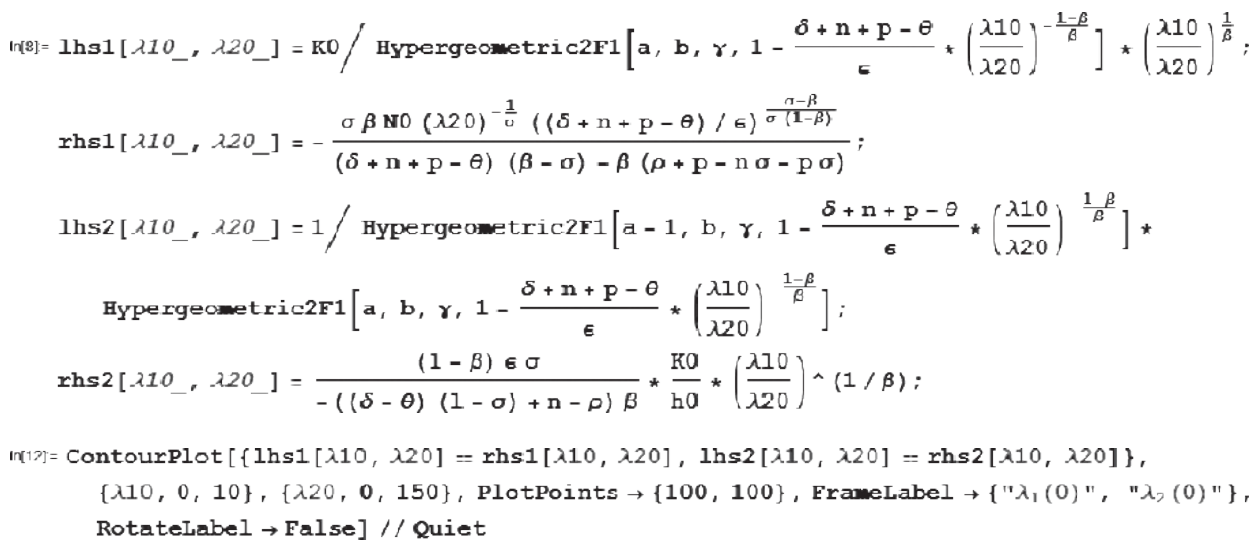




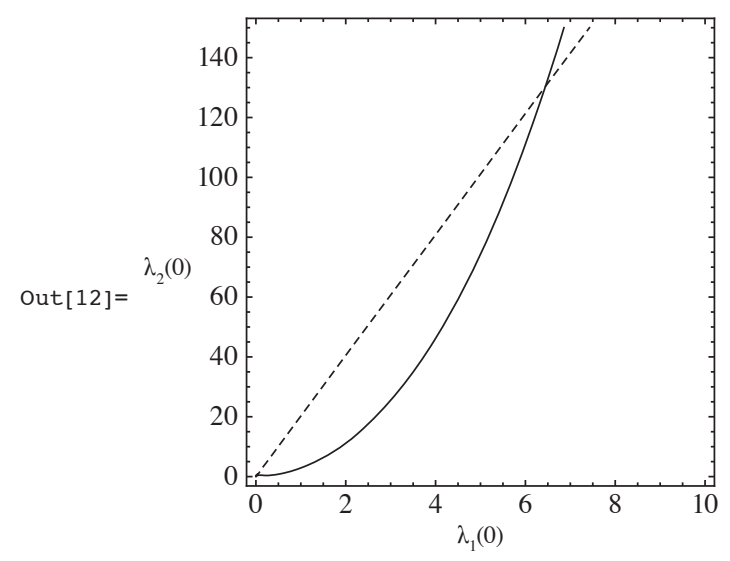

Rys. 2. Krzywe wyznaczone przez równania układu (16) i (17) (dla wartości parametrów z [Boucekkine i Ruiz-Tamarit 2004])

Źródło: opracowanie własne.

$\mathrm{Z}$ rys. 2 odczytujemy przybliżone wartości dodatnich mnożników Lagrange’a $\lambda_{1}(0) \approx 6$ i $\lambda_{2}(0) \approx 130$.

$\ln [13]=\operatorname{FindRoot}[\{\operatorname{lhs} 1[\lambda 10, \lambda 20]==\operatorname{rhs} 1[\lambda 10, \lambda 20], \operatorname{lhs} 2[\lambda 10, \lambda 20]==\operatorname{rhs} 2[\lambda 10, \lambda 20]\}$, $\{\{\lambda 10,6\},\{\lambda 20,120\}\}]$

Outr13k= $\{\lambda 10 \rightarrow 6.43694, \lambda 20 \rightarrow 130.024\}$

Wstawiając powyższe wartości mnożników do wzoru (14), możemy narysować ścieżki czasowe $K$ i $K^{\prime}$ (rys. 3 i 4) oraz obliczyć wartości tych funkcji w wybranych momentach.

$$
\begin{aligned}
& \ln (14)=\lambda 10=6.43694 ; \lambda 20=130.024 ; \\
& \ln \left[15 t-R\left[t_{-}\right]:=\mid K 0 *\left(\frac{\lambda 10}{\lambda 20}\right)^{\frac{1}{\beta}} *\left(\frac{\epsilon}{\delta+n+p-\theta}\right)^{\frac{1}{1-\beta}} *\right. \\
& \left(\text { Hypergeometric2F } 1\left[\mathbf{a}, \mathbf{b}, \gamma,\left(1-\frac{\delta+\mathrm{n}+\mathrm{P}-\theta}{\epsilon} *\left(\frac{\lambda 10}{\lambda 20}\right)^{\frac{\beta-1}{\beta}}\right) \star \operatorname{Exp}\left[-\frac{(1-\beta)(\delta+\mathrm{n}+\mathrm{P}-\theta)}{\beta} t\right]\right]\right. \\
& \text { Hypergeonetric2F1 } \left.\left[\mathrm{a}, \mathrm{b}, \gamma, 1-\frac{\delta+\mathrm{n}+\mathrm{p}-\theta}{\epsilon} *\left(\frac{\lambda 10}{\lambda 20}\right)^{\frac{\beta-1}{\beta}}\right]\right) \text { * } \\
& \operatorname{Exp}\left[\frac{(\delta+\mathrm{n}+\mathrm{p}-\theta)(\beta-\sigma)-\beta(\rho+\mathrm{p}-\mathrm{n} \sigma)}{\beta \sigma} t\right] * \\
& \left(-1+\operatorname{Exp}\left[\frac{(1-\beta) *(\delta+\mathbf{n}+\mathbf{P}-\theta)}{\beta} t\right]+\frac{(\delta+\mathbf{n}+\mathbf{P}-\theta)}{\epsilon} \star\left(\frac{\lambda 10}{\lambda 20}\right)^{\frac{\beta-1}{\beta}}\right)^{\frac{1}{1-\beta}}
\end{aligned}
$$

$\ln [16]:=\operatorname{Plot}[K[t],\{t, 0,50\}, A x e s L a b e l \rightarrow\{" t ", " K(t) "\}]$ 


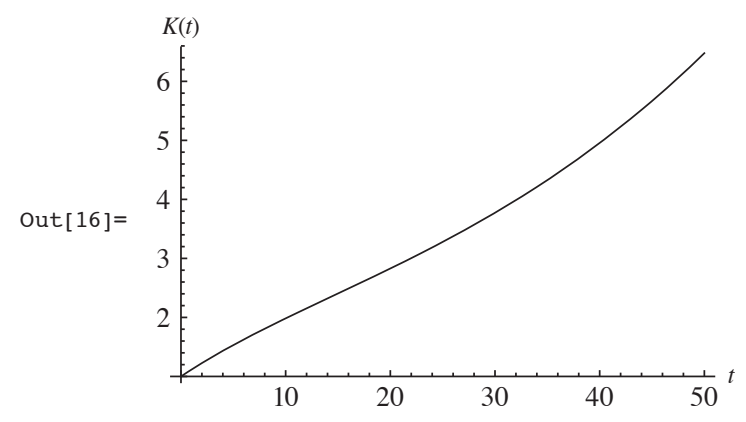

Rys. 3. Ścieżka czasowa kapitału fizycznego $K$ w modelu Lucasa-Uzawy (dla wartości parametrów z [Boucekkine i Ruiz-Tamarit 2004])

Źródło: opracowanie własne.

$\ln [17]=\{K[0], K[10], \mathbf{K}[50]\}$

Out[17] $=\{1 ., 1.98459,6.47753\}$

$\ln \left[18 \mathrm{i}:=\operatorname{Plot}\left[K^{\prime}[t],\{t, 0,50\}\right.\right.$, PlotRange $\left.\rightarrow A l l, A x e s L a b e l \rightarrow\left\{" t ", " K^{\prime}(t) "\right\}\right]$

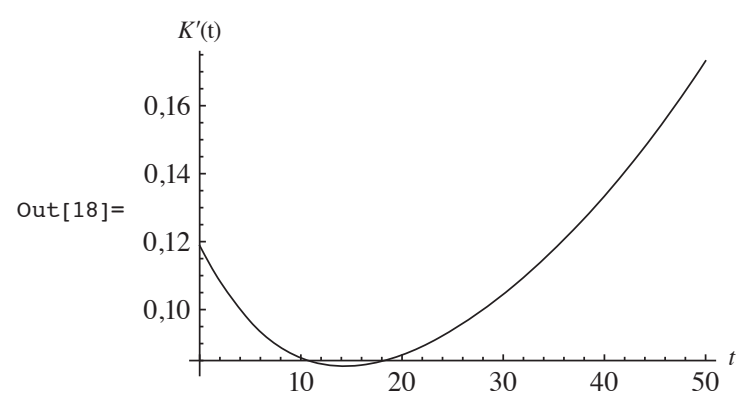

Rys. 4. Wykres pochodnej $K^{\prime}$ w modelu Lucasa-Uzawy (dla wartości parametrów z [Boucekkine i Ruiz-Tamarit 2004])

Źródło: opracowanie własne.

$\ln [19]=\left\{K^{\prime}[0], K^{\prime}[10], K^{\prime}[50]\right\}$

Out119\}= $\{0.118843,0.0857851,0.17318\}$

W analogiczny sposób można wyznaczać wartości i rysować ścieżki wzrostu pozostałych zmiennych modelu, korzystając $\mathrm{z}$ formuł podanych w [Boucekkine i Ruiz-Tamarit 2008]. 


\section{Uwagi końcowe}

W artykule przedstawiono zaledwie skromną próbkę możliwości programu Mathematica jako narzędzia wspomagającego ilościową i jakościową analizę matematycznych modeli wzrostu gospodarczego lub ogólniej - dynamikę ekonomiczną. Więcej przykładów oraz informacje dotyczące stosowanych w tekście instrukcji programu Mathematica można znaleźć m.in. w [Zawadzki 2012] oraz na stronie internetowej producenta programu www.wolfram.com.

\section{Literatura}

Boucekkine R., Ruiz-Tamarit J.R. [2004], Special Functions for the Study of Economic Dynamics: The Case of the Lucas-Uzawa Model, „CORE Discussion Paper”, No. 84, http://dx.doi.org/10.2139/ssrn.688904.

Boucekkine R., Ruiz-Tamarit J.R. [2008], Special Functions for the Study of Economic Dynamics: The Case of the Lucas-Uzawa Model, ,Journal of Mathematical Economics", vol. 44, http://dx.doi.org/10.1016/j.jmateco.2007.05.001.

Korn G.A., Korn T.M. [1983], Matematyka dla pracowników naukowych i inżynierów, cz. 1, PWN, Warszawa.

Mankiw N.G., Romer D., Weil D.N. [1992], A Contribution to the Empirics of Economic Growth, ,Quarterly Journal of Economics”, vol. 107, http://dx.doi.org/10.2307/2118477.

Tokarski T. [2011], Ekonomia matematyczna. Modele makroekonomiczne, PWE, Warszawa.

Zawadzki H. [2012], Atraktory w modelach równowagi i wzrostu gospodarczego, Placet, Warszawa.

\section{The Analysis of the Dynamics of Economic Growth Models with Mathematica} (Abstract)

Differential equations and optimal control theory are the basic tools of the mathematical theory of economic growth. The aim of this paper is to show (using the example of the Mankiw-Romer-Weil and Lucas-Uzawa growth models) some capabilities of Mathematica in the symbolic and numerical solving of differential equations, calculating optimal values of integral functional (discounted lifetime utility) when only numerical optimal solutions are known, the symbolic differentiation of solutions given in terms of hypergeometric Gauss functions and the graphical presentation of solutions to differential equations.

Keywords: Mathematica, differential equations, economic growth models, optimal control. 